\title{
Methodological approaches for interviewing elites
}

\section{William S. Harvey}

Full citation: Harvey, W.S. (2010). Methodological Approaches for Interviewing Elites.

Geography Compass, 4(3): 193-205.

\begin{abstract}
This paper explores some of the methodological strategies for interviewing elites. The focus is on researching elite members, preparing for interviews and gaining access, as well as the associated power relationships. Examples are drawn from across the social sciences and from the author's doctoral and post-doctoral work with over one hundred members of business elites. It is argued that researchers should be more attentive towards the following three areas. First, providing flexibility when designing research projects and conducting interviews. Second, ensuring transparency when communicating with elite members. Third, maintaining good etiquette with all participants to ensure the highest professional standards. The overall aim of the paper is to provide an introduction for those who are new to the field of interviewing elite subjects.
\end{abstract}

\section{Introduction and literature review}

In the last few decades social scientists have increasingly turned their attention towards the role of elite members within society, which has led to a growth of work on some of the methodological challenges of interviewing this group. One of the reasons for 
this growth of interview-based work on elite members is that researchers have wanted to analyse the behaviour of these respondents more closely because unlike other methods interviews have a strong emphasis on intimacy between the researcher and interviewee (Clark, 1998). This growth of interviewing has also arisen because elite workers are considered critical in shaping the policies and characteristics of organizations. In addition, scholars have argued that interviews can provide a different analytical lens for understanding firms (Schoenberger, 1991). It is also considered a more efficient means of obtaining qualitative data from elites than other methods such as questionnaires and focus groups, which can be more time-consuming. In the finance industry, for example, Clark (1998) suggests that some workers like to be interviewed because it is a sign of their status within the firm or industry. All this is not to say that other types of methods are not important for gathering information on elites, but effective interviewing seems to generate novel and insightful data. Intensive forms of analysis such as interviewing are effective because they can generate responses that would be difficult to obtain through other more traditional methods. However, the skill of a social scientist is understanding and applying a range of methods and techniques, and combining them in a way that respects their compatibilities and incompatibilities (Sayer, 1989, p. 268). However, although there have been some groundbreaking texts on these methodological challenges (Dexter, 1970; McDowell, 1998; Ostrander, 1993), there have been fewer attempts to bridge these different experiences across the social sciences. This is important because interviewing elites is of concern to scholars in a range of social science disciplines and yet much of the literature on researching elites has been intra- rather than interdisciplinary. Richards (1996) and Goldstein (2002), for example, have provided highly 
practical advice on different approaches to researching political elites, but there is very limited reference to the work and interviewing strategies of other scholars outside of political science. Having said this, Cochrane (1998) and Woods (1998) have drawn on texts and provided strong conceptual and theoretical critiques of elite research from across the social sciences.

There has been scant guidance in the theoretical literature about how to prepare for interviewing elite subjects and what type of challenges to expect and strategies to adopt. McDowell (1998), for example, discusses some of the challenges that she faced as a female researcher interviewing predominantly male business elites in the City of London. This is one of the few texts which addresses the challenges researchers face when interviewing elite members, which is surprising given that scholars, including postgraduate and postdoctoral researchers, appear to be increasingly focusing their attention on this group (Berry, 2002). Furthermore, elites hold highly valuable insights into organisations and therefore it is vital that scholars adopt appropriate methods to engage with this group.

There are two broad groups of literature on interviewing methods. The first are 'instructional texts' which analyse some of the techniques surrounding preparing for and conducting interviews. They include information about selecting participants, gaining access and conducting interviews in particular places (Lofland \& Lofland, 1995). Despite some work in this area (Peabody et al., 1990; Aberbach \& Rockman, 2002; Rivera et al., 2002; Ostrander, 1993), there have been very few recent practical guidelines for those new to interviewing elites. Although there are many general practical texts on interviewing techniques (Bryman, 2004; Silverman, 2006), what is not 
clear is how these techniques compare to the challenges of interviewing elite subjects. The second group of literature are critical reflections in the social sciences surrounding the power relationships between the researcher and the interviewee (Elmwood and Martin, 2000, p. 650). These texts examine the construction of power between different groups and how power is rooted in social identities such as gender, ethnicity and class (Katz, 1994). Schoenberger (1991, p. 182), for instance, argues that corporate interviews are a balance between the interviewer, who is generally in greater control because he or she sets the agenda, and the respondent, who, in the case of elites, is often used to exerting control and authority over others. This paper seeks to address both the pragmatics of researching elite subjects as well as the challenges of addressing power relationships.

The paper draws upon the experiences of scholars across the social sciences as well as my own experiences of interviewing over one hundred CEOs, Vice-Presidents and Directors during my doctoral and post-doctoral work. I recognise that the strategies that work for some researchers and elites may not be effective for others. Indeed, one of the major challenges from the literature on elite subjects is distinguishing between proven strategies that have demonstratable benefits and anecdotal experiences that are effective in individual cases. This paper combines my own anecdotal experiences of interviewing highly skilled migrant elites across different economic sectors in the US and Canada with the strategies and anecdotes of other scholars across the social sciences who have interviewed a range of elite groups. This paper encourages those new to interviewing elites to think critically about some of the different approaches to researching this group. 
Inevitably, some of these approaches are not exclusive to those researching elite groups and therefore what follows is also applicable to the general interviewer.

The paper begins by introducing and addressing the problem of defining elite members. The remainder of the paper focuses on two aspects of researching this group. First, I suggest some strategies for gaining access to elite groups.I raise the challenges of researching subjects including preparing for interviews. Second,

\section{Defining elites}

Historically, many social science disciplines have skewed strongly towards quantitative research, thereby overlooking the experiences of elites who were not large enough in size to be included in sample surveys (Savage \& Williams, 2008). In the last few decades, there has been a growing recognition of the importance of both quantitative and qualitative research (Bryman, 2004; Creswell, 2003). This has led in turn to a resurgence of ethnographic research including case studies, interviews, participant observation and longitudinal studies. Within this body of research, there has also been growing attention towards the role of elite members. Yet, surprisingly much of this literature has overlooked some of the methodological challenges and implications of researching this group.

One of the pioneers of elite interviewing methods was Anthony Lewis Dexter (1970, 2006). Although he argued that interviewing this group was an important research tool within the social sciences, he was clear that it was not always the most appropriate method to understand this group. In his earlier work, he seemed to suggest that junior researchers should avoid interviewing elite members because they are "ill-prepared" and 
"needlessly take up the time of important persons" (Dexter, 1964, p. 557). Since this debatable assertion, there has been little if any commentary from other scholars concerning whether inexperienced researchers should interview elite groups or leave this research to more experienced interviewers. At the same time, interviewing elite members has become more common and yet is rarely taught in graduate schools (Berry, 2002).

There is much confusion and debate surrounding the definition of elites. Indeed, a major criticism of Dexter's (1970) work is that he said little about what constitutes elite subjects (Richards, 1996). They are often regarded as numerical minorities because they frequently occupy positions at the top of the employment and income pyramid (Woods, 1998). However, an individual's position within a company, for example, is not exclusively an indicator of elite status because certain actors are deemed elite members because they hold strategic positions within a social network and therefore act as important connectors and bridges between social structures (Burt, 1992). Furthermore, elite status may be embedded within place and time. A person, for example, might be considered to qualify as an elite member in one particular region but not in another. In addition, this group is by no means spread evenly across geographical space and elite status is not static since individuals can gain or lose their status over time.

The boundaries of defining elites are also changing. As Savage and Williams (2008, p. 13) rightly point out, $70 \%$ of FTSE 100 companies in the early 1980 s are no longer in the index today. Although some senior managers have subsequently become part of elite groups through working for other companies, many more have retired or been made redundant and are therefore no longer the occupants of corporate power today. Table 1 shows twenty different job titles of senior managers from my doctoral work in 
2006 on highly skilled British and Indian scientists working in Boston's pharmaceutical and biotechnology sector. The variety of senior management titles within one regional economy demonstrates the difficulty of defining elite groups. To make matters even more problematic, these job titles are not synonymous from one company to another. A Senior Vice-President of Company A, for example, may well have a very different job function to a Senior Vice-President of Company B, despite both holding the same job title. In short, defining elites is such a challenging task that some scholars have critiqued the usefulness of the term (Smith, 2006; Woods, 1998). Defining elites is likely to be even more difficult when comparing elites across different corporations, sectors and national boundaries because their job titles might prove yet further dissimilar. In this paper, I use the term elites to describe those business people who at the time the research was carried out predominantly occupied senior management positions and were influential decision-makers for their companies or leading consultants for other firms in Boston and Vancouver, which were the cities I was studying for my doctoral and postdoctoral work. I apply the term more broadly when drawing on examples from the theoretical literature to reflect the diversity of interpretations. 
Table 1: Senior Management Positions

$\begin{array}{llll}\text { Chief Executive Officer } & \text { President } & \text { Founder } & \text { Principal } \\ \text { Chief Financial Officer } & \text { Chief Business Officer } & \text { Chief Scientific Officer } & \text { Chief Operating Officer } \\ \text { Senior Director } & \text { Director } & \text { Executive Director } & \text { Executive Project Director } \\ \text { Associate Director } & \text { Senior Vice-President } & \text { Vice-President } & \text { Executive Vice-President } \\ \text { Divisional Vice-President General Manager } & \text { Head of Marketing } & \text { Head of Research }\end{array}$

\section{Gaining access}

The success of gaining access to elite subjects depends a great deal on serendipity, social networks as well as particular circumstances (McDowell, 1998, p. 2135). However, the location and length of interviews, which I discussed above, can also affect one's success in gaining access (Demeritt \& Dyer, 2002; Elwood \& Martin, 2000). Researchers should attempt to pursue as many different avenues as possible in a polite, yet persistent and opportunistic manner (Yeung, 1995). During my Ph.D fieldwork one gatekeeper $^{\mathrm{i}}$ arranged for me to interview seven scientists consecutively in one morning at a large pharmaceutical company. Diagram 1 shows some of the different routes I used to maximise the opportunity of gaining access to British elite workers around Vancouver. These avenues were not of equal importance in helping me to gain access to respondents. Sports clubs, for example, were very helpful because I was able to forge new social networks and gain rapport with elite respondents outside of a business environment. In contrast, the British Consulate was of limited assistance because of the confidential and bureaucratic barriers of disclosing personal details. An important methodological advantage of pursuing multiple avenues for gaining access to elite populations is that it reduces the potential bias of only speaking to people within a particular social network. 
Diagram 1: Gaining access to British elite workers around Vancouver

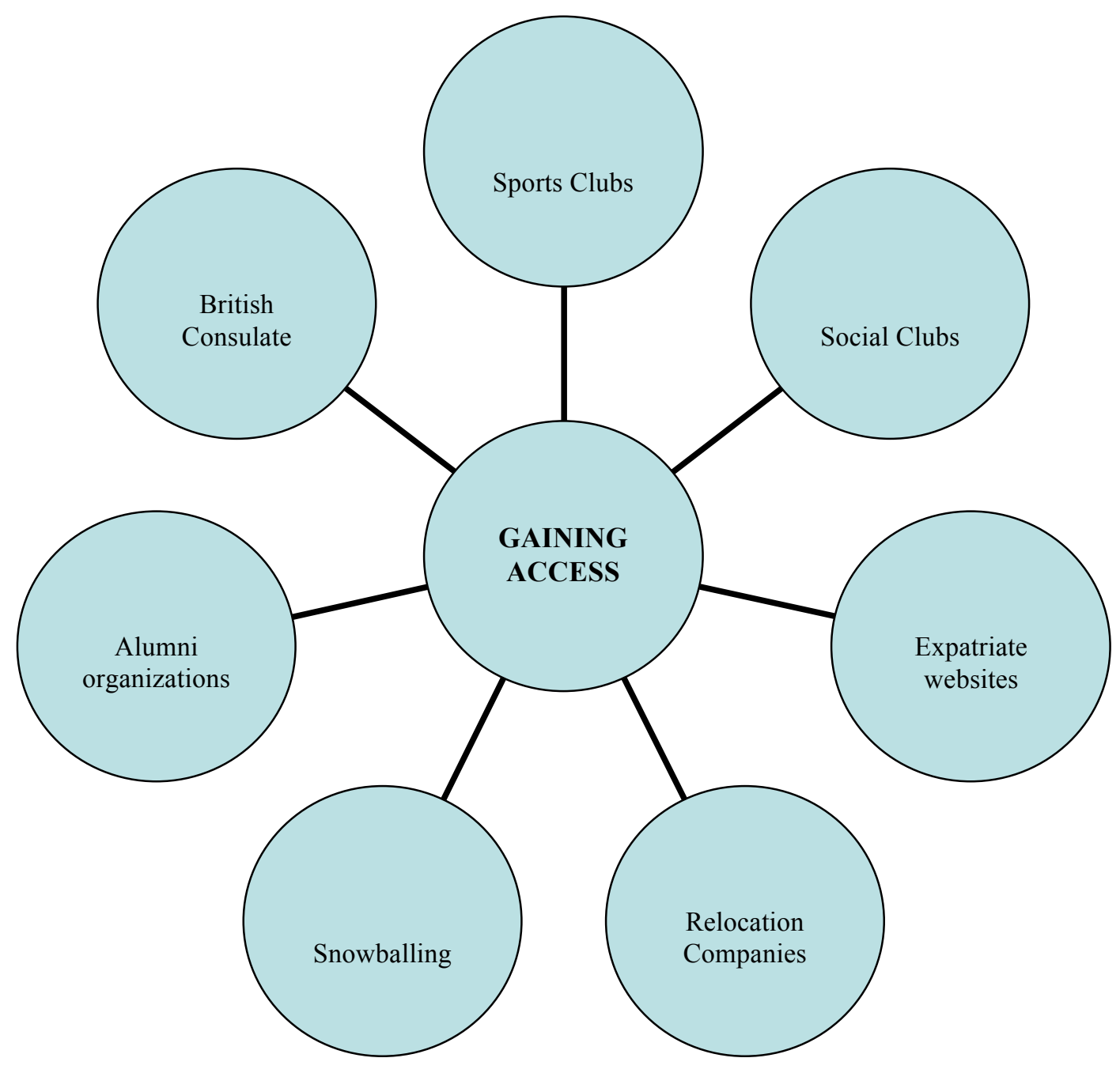

University ethics boards can considerably restrict and alter the dynamics of the research design process. Many North American universities, for example, require that researchers do not make initial contact with respondents by telephone, that researchers receive a complete written consent form from respondents before they participate in the research, and finally that if respondents recommend other people for researchers to contact then they must receive permission from them first before providing their names and contact information. These types of conditions make it even more difficult for scholars to gain 
access to elite members. In addition, a researcher's opportunity to snowball further contacts is significantly reduced when elite subjects need to gain permission from their contacts first before they can pass on their personal details to researchers. These kinds of ethical requirements significantly hamper the ability of researchers to gain access to elite groups. This is problematic for economic geography which has a strong tradition of adopting elites interviews as a vehicle for interrogating the social, economic and political power of major economic actors within organizations. More generally, such ethics restrains also arguably restrict the ability of scholars to adopt critical research because it requires them to conform to a particular standard for transparency purposes rather than maintaining autonomy in their research design.

During the late 1990s there were a number of geographic debates on interviewing elites (Herod, 1999; McDowell, 1998; Woods, 1998). Since this time, there have been major developments in ICT technology and in particular the use of the Internet and e-mail have become widespread within the workplace, whereas in the late 1990s they were in the early stages of development. This is critical because improvements in technology have facilitated and altered the way in which researchers identify as well as gain access to elite members. This has become even more the case with the advent of handheld mobile devices, which enable users to access the Internet and their e-mails remotely. This is not to suggest that traditional methods of gaining access to elites such as social networks are not used today, but they are also re-worked in different ways through, for example, business social networks websites such as LinkedIn. James (2006, p. 298) found that mimicking the email address format of certain contacts (e.g. john.smith@company.com) 
within a firm and applying that format to a person whom he wanted to contact at the same company (e.g. david.thompson@company.com) or e-mailing the webmaster of the company and generating a response from the webmaster's e-mail address (e.g. webmaster@company.com) enabled a very high proportion of his e-mails (around 90\%) to reach the right person. He argues that there is never a wrong time to contact people because they will open an e-mail when they are ready. However, researchers should be aware that at certain points of the day, week, month and year, and depending on the sector and the individual, elite members will have a greater volume of work and e-mails than at other times. Although this is not always straightforward to predict, some commonsense should prevail (e.g. if possible, avoid contacting accountants near the end of the tax year or politicians around the time of an election).

Researchers should be well-prepared to summarise their research briefly in nonacademic jargon to subjects and appointment secretaries. It is critical not to be put off by gatekeepers as one of their roles is to protect the interests of their company and managers (Peabody et al, 1990). Personal assistants (PAs), for example, often make the decision of whether someone should speak to their bosses or not. In most cases they also have complete access to and control of the diaries of elites. Rather than perceiving gatekeepers as barriers, I try to see them as potential opportunities. One gatekeeper wanted to meet with me to establish the nature of my research and he spent approximately 45 minutes asking me questions about all aspects of my work. Having satisfied his questions, he subsequently contacted around 60 people, the majority of whom agreed to participate in my research because of his reputation and positive referral. 
In other words, gatekeepers are capable of opening as much as closing doors to elite respondents, provided they approve of the prospective research.

There has been much debate within the social sciences concerning the advantages and disadvantages of being an insider or outsider. Traditionally, scholars have argued that being an 'insider' can provide an advantage because a person holds a shared sense of belonging to respondents (Hill-Collins, 1990). However, 'outsiders' arguably hold the advantage of not belonging to a group and therefore are more objective and better able to observe behaviour (Fonow \& Cook, 1991). Some scholars find that being an outsider can be an advantage when seeking to gain access to respondents. Herod (1999), for example, argued that he received a warmer reception as an outsider conducting research on trade union officials in Eastern Europe than as an insider in the US.

It is possible that a researcher can be both an insider and an outsider, according to Mullings (1999). Junior researchers, for example, can be seen as at the 'cutting edge' or 'inexperienced' and senior researchers can be seen as 'world experts' or 'out-of touch'. When I was studying British expatriates in Boston and Vancouver I found myself simultaneously as an insider because I was a British expatriate and as an outsider because I was a young researcher in my mid-twenties compared to my respondents who were mainly in their forties. I found when I was meeting younger respondents, they would suggest meeting in more informal settings (e.g. bars), whereas with older respondents they would suggest meeting in more formal venues (e.g. office meeting rooms). These differences may have been because of generational preferences or because respondents who were a similar age to me were more comfortable meeting in a convivial environment. This is important because interview settings may lead to different types of 
data being disclosed, which is often overlooked: "[...] because it is the content of interviews that is seen to be of primary interest, not how that content was achieved by speakers within the interview setting" (Roulston et al., 2003, p. 659). Judging an interviewer's positionality is a slippery process and rather than focusing on dualisms it is arguably more appropriate to analyse the power relationships between the researcher and elite subjects as a 'sliding scale of intimacy' (Herod, 1999, p. 326). Elwood and Martin (2000, p. 649) refer to the 'micro-geographies of spatial relations and meaning' where multiple scales of social relations intersect during an interview. Positionality is also not static. Parry (1998, p. 2155), for instance, found herself during the course of her fieldwork promoted to fulfil the strict criteria of membership of an elite network. Equally, other scholars may quite as easily lose their insider status while conducting elite research. In addition, people can hold more than one positionality at any given time:

For instance, in one location a participant may assert one identity, such as that of political official, and in another location answer interview questions from a different perspective, such as that of concerned parent (Elwood \& Martin, 2000, p. 653).

It is not only the positionality of the researcher in relation to the elite respondent, but also the positionality of the elite respondent in relation to the firm which can have critical implications in terms of gaining access. Elite members typically hold senior management positions within firms and therefore unlike other workers they are arguably more likely to represent the position of the firm rather than their own individual viewpoint. Indeed, senior managers receive extensive internal training on how to communicate the activities of their organization. This is critical because it can be challenging for researchers to obtain the personal views of elites as opposed to the 
company line on particular issues. Gaining access can also be problematic because of an elite's positionality within the firm. A CEO of a multinational corporation may personally be willing to be interviewed by a researcher, for example, but does not agree to meet with the researcher because of the expectations and time pressures he or she receives from other company stakeholders such as shareholders, partners and clients. In this respect, an elite member's positionality within the firm and his or her accompanying power within the organization can have significant bearings on a researcher's ability to gain access.

University affiliation may have both positive and negative implications in terms of gaining access to elite networks. Surprisingly, there has been a relative lack of discussion about this within the elite literature. Herod (1999) is one of the few exceptions and he provides an example of how researchers from northern universities in the US may be perceived as 'pesky Yankees', whereas researchers from southern universities in the US may be perceived as 'backwards' and out in the 'sticks'. When conducting my doctoral research around Boston I found that being a researcher from the University of Cambridge and a visiting scholar at Harvard University enabled me to gain access to elite members, not only because a number of them (nine percent) were former students of both universities but also because I was able to attend events organised by members of the Oxford and Cambridge Club and the Harvard Faculty Club. Similarly to McDowell (1998), I am not arguing that if I was affiliated to other universities then I would not have been able to gain access to this group. Indeed, my links to these universities may have meant that some potential respondents, a number of whom refused to be interviewed, did not want to speak with me because I was affiliated with what they perceived to be elitist 
and less down-to-earth universities (see Herod, 1999, p. 321). Furthermore, it is important to recognise that it is easier to demonstrate how an affiliation to a university was helpful in gaining access, but much harder to show that an affiliation to a university was restrictive in gaining access to elite subjects. Researchers should be aware that their institutional affiliations will be received differently which in turn will affect their experiences of gaining access to this group.

The academic discipline of researchers will also affect their experiences of gaining access to elite members. Depending upon the research goals and the professional interests of respondents, researchers from different social science disciplines may have varying experiences in gaining access to this group. When conducting my doctoral research on Boston's pharmaceutical and biotechnology sector, a number of my respondents assumed that I came from a Business and Management background and when I said that my training was largely in Economic Geography, they would typically ask 'How is this work related to Geography?' McDowell's (1998, p. 2138) respondents also found it bewildering that "[...] geographers should have any interest at all in workplace organization." Importantly, the issue of respondents not identifying with a particular academic discipline is prevalent across the social sciences and can affect participation rates.

\section{Researching subjects and interview preparation}

A common challenge for interviewers is experiencing situations that they do not expected when they are planning their research (Roulston et al., 2003). On a number occasions, for example, one of my interviewees has turned-up late which has challenged 
my ability to conduct a good interview and put pressure on me to attend subsequent interviews on time. Roulston et al. (2003) also found that some of their students struggled to get to the crux of their interview questions because they had become distracted. When corresponding with elite members, in most cases I ask when it would be most convenient for them to speak with me (see also Zuckerman, 1972), but I also ensure that I give myself ample time to attend another interview in the case of delays. If a respondent agrees to participate in the research but does not suggest a time and date after an earlier request, then I take the initiative while still showing flexibility to fit in with his or her schedule. At this point it is also appropriate to state how long the interview will take as this is a frequent question. Researchers should be honest with respondents although there is some leeway to "[...] specify a time a little, but not much, less than the normal time which interviews on the particular project take" (Dexter, 2006, p. 49). It is also central to be realistic about how much time to expect to speak with elite members. I generally ask for about thirty minutes and my interviews typically last for approximately forty-five minutes. I have found that these times tend to be shorter for telephone interviews and for interviews with chief executives. Ostrander (1993, p. 21) asks for "[...] about an hour and a half in terms of time", but this is most likely because even at the time of writing her paper she was a well-renowned scholar and held a good deal of experience in interviewing members of elites. These two attributes most junior scholars do not share and therefore in my situation asking for anything over an hour would have been unrealistic. Conti \& O’Neil's (2007, p. 71) experience of a government official beginning an interview by saying "What can I tell you in 45 minutes?" can be a typical question that an elite member might ask. 
One of my respondents in 2006 asked me over the telephone what my doctoral research was about and I replied by saying that I was comparing why British- and Indianborn scientists moved to Boston, Massachusetts, what their experiences have been of finding work in the pharmaceutical and biotechnology sector, and whether they had any intentions of returning to and/or investing in their home countries in the future. This interviewee responded to my summary by speaking uninterrupted for five minutes addressing these issues before immediately hanging up the telephone. This serves to highlight firstly that elite members, like other groups, often try to dictate the conditions of an interview and secondly that the number of interviews is not necessarily an indicator of high quality research. On some occasions an interviewee might provide more time than expected and researchers should be flexible and prepared to use this as an opportunity to go into more detail on particular topics (Peabody et al, 1990). One of my interviewees made the point that if you are conducting a good interview then he or she will usually be prepared to push other things back. He gave an example of when he was meeting a chief executive who did just this and made a senior cabinet minister wait for fifteen minutes. On other occasions, I have been unexpectedly called and asked if the interview can be conducted immediately. In many other circumstances, my interview has been postponed. In both cases, my flexibility was appreciated by the respondent and therefore helped to achieve a high quality interview.

When communicating with elite members concerning a research project, in the vast majority of cases researchers are advised to be as open as possible with their research goals and attempt to instil trust and a common understanding about what they hope to achieve (McDowell, 1998; Oinas, 1999). Feminist scholars have been 
particularly attentive to these issues through recognising that the power dynamics between an interviewer and an interviewee will have direct implications on the type of knowledge that is created (Conti \& O'Neil, 2007). One of Roulston et al's. (2003, p. 650) students, Jolene, said that she should have informed her participants that she was taking notes because when her interview subject saw her writing she stopped talking which meant that Jolene had to explain what she writing. In this case, greater transparency about what the respondent should expect from the interview would have prevented Jolene from having this uncomfortable pause during the interview.

In certain circumstances, both the interviewer and interviewee will be silent on certain issues because they are either unable or unwilling to disclose certain information. These potentially awkward scenarios can be overcome in some measure through the interviewer discussing any shared interests he or she has with the interviewee or through using something that an interviewer has read or seen that might help to break the ice and gain rapport (Peabody et al, 1990; Richards, 1996). Having said this, at times elite members will often provide the official company position rather than their personal opinion. In such instances and if possible, cross-checking and triangulating different kinds of evidence is an important form of verifying the reliability of the data. Roulston et al. (2003, p. 661), for example, found that some of their students: “[...] tended to accept a participant's response and move directly to the next question rather than ask for elaborations or clarifications of meaning." On other occasions, because elite members are at the top of the corporate hierarchy and used to being asked questions and controlling conversations, they will often respond with unsatisfactory answers which are not relevant to the interviewer's research questions. At the very least and in order to increase 
common understanding, before an interview I tried to make it clear to my respondents: who I was, where I was working, what the nature of my research was, who was sponsoring me, approximately how long my interview would take, how the data would be used, how the results would be disseminated and whether the information would be attributed or anonymous.

The location of an interview can influence the type of information respondents are prepared to disclose. Within the workplace, for example, respondents may be less willing to disclose confidential information or provide additional time, for fear of being overheard or because their colleagues expect them to be performing other duties (McDowell, 1998). Dexter (2006, p. 48) argues that scholars should prioritise the workplace over the home "[...] because some interviewees will let their families come in and out freely, and generally will tolerate interruptions which they would not in their offices." I disagree on this point because some elite members are equally if not more likely to be interrupted during business hours by colleagues than they are by family members outside of standard work hours. Furthermore, interviews outside the workplace are easier to expand as well as to broach more confidential information:

[...] when we interviewed organization directors and other staff members in their homes or in public places outside of their offices, they talked more freely about their opinions outside of the organizational goals or missions (Elwood \& Martin, 2000, p. 655).

The best location to interview elite members is likely to vary greatly depending on a number of factors, including the research context, the type of respondent being interviewed as well as the predicted power relationship between the interviewer and respondent. Therefore, it is important to be aware of the strengths and weaknesses of 
interviewing in different locations. If researchers are interviewing in a 'neutral' venue such as a café or bar then they might want to avoid areas that are either too quiet, which may make respondents tentative about disclosing certain types of information, or that are too noisy, making it difficult to speak to and hear respondents. If I am meeting someone in a café or bar then I plan to arrive ten or fifteen minutes early so that I can find a suitable place where I feel comfortable asking my questions.

Although piloting research is strongly encouraged within the social sciences (Yin, 1989), there is very little guidance concerning whether interviewers should be encouraged to conduct pilot work on elite members. Peabody et al (1990) suggest that researchers should ask their questions to colleagues and friends before posing them to elite groups, which can help to clarify and refine questions. However, it is unclear to me whether it is generally encouraged to do pilot work on this group. This is critical because piloting is beneficial to all elements of the research design, including the wording of questions, the order of questions, the reduction of non-response, the costs and time involved, the coding and quantifying of responses, as well as the analysis. If piloting is not encouraged because elite members have little time available then surely this means potentially poorer quality questions since they have not been pre-tested? In short, there is a lack of academic guidance concerning pilot work on elite members. I would suggest that inexperienced researchers who decide to interview this group as part of their research speak to them towards the end of their fieldwork when they are more familiar with their research and interview questions, not least because elite members do not 'suffer fools gladly' (Richards, 1996). 
It is generally agreed that elite subjects prefer not to be asked closed-ended questions (Aberbach \& Rockman, 2002, p. 674). Schoenberger (1991, p. 183) argues:

Respondents are likely to feel less frustrated if they are able to explain exactly what they mean in their own terms rather than trying to fit themselves into the terms of reference proposed by the researcher.

As a result, in most cases interviewers should avoid asking too many formulaic questions and instead focus more on achieving a conversational flow. Rivera et al (2002) argue that open-ended questions can be successfully followed-up by closed-ended questions. During my doctoral and post-doctoral research I wanted to collect both quantitative and qualitative data on highly skilled professionals and therefore asked open-ended questions followed by closed-ended questions. When seeking to understand why British expatriates might want to return to the UK, for example, I started with an open-ended question: 'Why would you return to the UK?' This gave respondents an opportunity to say in their own words what the key driving forces were in influencing them to return. I followed this question up with a closed-ended question: 'Please rank from 0 to 10 the importance of each of the following factors that might influence you to return to work in the UK: a) Professional opportunities in the UK; b) Family considerations; c) Culture and lifestyle in the UK; d) Government or company incentives to return to the UK; e) Desire to contribute to the economic development of the UK'. This closed-ended question enabled me to generate some quantitative data on factors that I considered of theoretical importance when I was designing my questions. I also found that elite members preferred to be asked open-ended rather than closed-ended questions, but if researchers only ask this group open-ended questions because of their preference then there is 
potentially a shortage of certain types of quantitative data from closed-ended questions, which can importantly complement the qualitative data obtained from open-ended questions.

Once the elite interviews have been completed, the way that the data is processed and analysed is important in terms of how it is interpreted and presented. Scholars are divided on the advantages and disadvantages of manual versus computerized data analysis. While I do not wish to enter this debate here, it is important to consider that in both types of analysis, particular words, intonations and emphasis can be highlighted or overlooked from interview transcripts. As Sayer (1989, p. 263) rightly indicates: “The power of analysis derives from its ability to explain much by little" and the researcher holds a significant degree of power in this storytelling from interviews. This power has a unique dynamic with elite interviews because these subjects typically hold a large amount of influence and sway within their firm and often try to shape the agenda of interviews because they are used to leading meetings. As a result, researchers have the challenging task of representing the views of elite respondents given this specific power relationship. Critically, the narrative presented is influenced by a number of factors including the author's own interests, time deadlines, and the author's audience (Sayer (1989). Arguably the context of interviews and how responses are given need particular attention because of the very specific power relationship between multiple subjects.

\section{Conclusions}

This paper complements the theoretical literature on interviewing elites by providing a number of practical guidelines for scholars new to researching this group. 
The focus of my argument has revolved around two areas. First, in gaining access, researchers should try and pursue as many avenues as possible, including using their own social networks. Researchers should also think about how their positionality, such as their institutional affiliation, may affect their ability to gain access to elite members. Second, in researching subjects and interview preparation. I showed that it is critical to have a detailed knowledge of the field including the respondent. Researchers should also be flexible in the design of their questions and as transparent as possible with subjects concerning the nature of their project. It is important to consider how the location of the interview as well as pilot work can improve the type of data gathered.

In terms of researching and gaining access to elite members, I would suggest that researchers should attempt to be more attentive to three areas. First, they need to be flexible in the design of their questions and the arranging of meetings. Second, transparency is important in terms of ethics and gaining the interviewee's trust. Third, maintaining good etiquette with different subjects throughout the research process is vital in order to achieve high professional standards. There is no single approach to interviewing elite subjects and the nature of the research and the personality of the interviewer and the interviewee, as well as the nature of the power relationship, should to a large degree shape individual approaches.

\section{Bibliography}

Aberbach, J. F and Rockman, B. A. (2002). Conducting and Coding Elite Interviews. PS: Political Science and Politics 35(4), pp. 673 - 676. 
Berry, J. M. (2002). Validity and Reliability in Elite Interviewing. PS: Political Science and Politics 35(4), pp. $679-682$.

Bryman, A. (2004). Social Research Methods. $2^{\text {nd }}$ ed. Oxford: Oxford University Press.

Burt, R. S. (1992). Structural Holes. Cambridge, MA: Harvard University Press.

Clark, G. L. (1998). Stylized Facts and Close Dialogue: Methodology in Economic Geography. Annals of the Association of American Geographers 88(1), pp. 73-87.

Conti, J. A. and O'Neil, M. (2007). Studying power: qualitative methods and the global elite. Qualitative Research 7(1), pp. 63 - 82.

Creswell, J. W. (2003). Research Design: Qualitative, Quantitative, and Mixed Methods Approaches. $2^{\text {nd }}$ ed. Thousand Oaks, California: Sage Publications, Inc.

Demeritt, D. and Dyer S. (2002). Dialogue, metaphors of dialogue and understandings of geography. Area 34(3), pp. 229-241.

Dexter, L. A. (1964). The Good Will of Important People: More on the Jeopardy of the Interview. Public Opinion Quarterly 108(1), pp. 556 - 563.

---. (1970). Elite and Specialized Interviewing. Evanston, Illinois: Northwestern University Press.

---. (2006). Elite and Specialized Interviewing. Colchester, UK: European Consortium for Political Research. 
Elwood, S. A. and Martin, D. G. (2000). 'Placing' Interviews: Location and Scales of Power in Qualitative Research. Professional Geographer 52(4), pp. 649-657.

Fonow, M, and Cook, J. (Eds.) (1991). Beyond Methodology. Feminist Scholarship as Lived Research. Bloomington: Indiana University Press.

Herod, A. (1999). Reflections on interviewing foreign elites: praxis, positionality, validity, and the cult of the insider. Geoforum 30, pp. $313-327$.

Hill-Collins, P. (1990). Learning from the outsider within the sociological significance of black feminist thought. In: Fonow, M. and Cook, J. (eds.), Beyond Methodology.

Feminist Scholarship as Lived Research. Bloomington: Indiana University Press, pp. 35 59.

James, A. (2006). Critical moments in the production of 'rigorous' and 'relevant' cultural economic geographies. Progress in Human Geography 30(3), pp. 289 - 308.

Katz, C. (1994). Playing the field: Questions of fieldwork in geography. Professional Geographer 46, pp. 67-72.

Lofland, J., and Lofland, L. (1995). Analyzing Social Settings: A Guide to Qualitative Observation and Analysis. $3^{\text {rd }}$ ed. Belmont, CA: Wadsworth, McDowell, L. (1998). Elites in the City of London: some methodological considerations. Environment and Planning A 30, pp. 2133 - 2146.

Mullings, B. (1999). Insider or outsider, both or neither: some dilemmas of interviewing in a cross-cultural setting. Geoforum 30,pp. $337-350$. 
Oinas, P. (1999). Voices and silences: the problem of access to embeddedness. Geoforum 30, pp. $351-361$.

Ostrander, S. A. (1993). Surely you're not in this just to be helpful. Access, Rapport, and Interviews in Three Studies of Elites. Journal of Contemporary Ethnography 22(1), pp. 7 $-27$.

Parry, B. (1998). Hunting the gene-hunters: the role of hybrid networks, status, and chance in conceptualising and accessing 'corporate elites.' Environment and Planning A 30 , pp. $2147-2162$.

Peabody, R. L., Hammond S. W., Torcom J., Brown L. P., Thompson C. and Kolodny R. (1990). Interviewing Political Elites. PS: Political Science and Politics 23, pp. 451 - 455.

Richards, D. (1996). Elite Interviewing: Approaches and Pitfalls. Politics, 16(3), pp. 199 -204 .

Rivera, S. W., Kozyreva, P. M., and Sarovskii, E. G. (2002). Interviewing Political Elites: Lessons from Russia. PS: Political Science and Politics 35(4), pp. 683 - 688.

Roulston, K., deMarrais, K. and Lewis, J.B. 2003. Learning to Interview in the Social Sciences. Qualitative Inquiry 9(4), pp. 643-668.

Savage, M. and Williams, K. (2008). Elites: remembered in capitalism and forgotten by social sciences. Sociological Review 56, pp. 1 - 24.

Sayer, A. (1989). The 'new' regional geography and problems of narrative. Environment and Planning D: Society and Space 7, pp. 253-276. 
Schoenberger, E. (1991). The Corporate Interview as a research method in Economic Geography. Professional Geographer 42(2), pp. 180 - 189.

Silverman, D. (2006). Interpreting Qualitative Data. $3^{\text {rd }}$ ed. London: Sage Publications.

Smith, K E. (2006). Problematising power relations in 'elite' interviews. Geoforum 37 , pp. $643-653$.

Yeung, H W C. (1995). Qualitative Personal Interviews in International Business

Research: Some Lessons from a Study of Hong Kong Transnational Corporations. International Business Review 4(3), pp. 313 - 339.

Woods, M, (1998). Rethinking elites: networks, space, and local politics. Environment and Planning A 30, pp. $2101-2119$.

Yin, R K, (1989). Case Study Research. (Sage Publications, London).

Zuckerman, H. A. (1972). Interviewing an ultra-elite. The Public Opinion Quarterly 36, pp. $159-175$.

${ }^{\mathrm{i}}$ I define a gatekeeper as a person who manages or constrains access and the flow of knowledge and information within an organisation. 